\title{
The Time-Varying Degree of Inflation Expectations Anchoring
}

\author{
Till Strohsal* \\ Rafi Melnick** \\ Dieter Nautz*
}

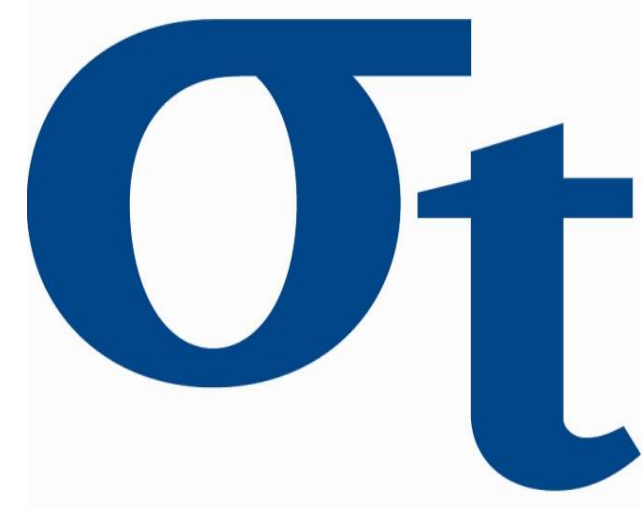

* Freie Universität Berlin, Germany

** The Interdisciplinary Center,IDC Herzliya, Israel

This research was supported by the Deutsche Forschungsgemeinschaft through the SFB 649 "Economic Risk".

http://sfb649.wiwi.hu-berlin.de ISSN 1860-5664 


\title{
The Time-Varying Degree of Inflation Expectations Anchoring
}

\author{
Till Strohsal $^{\mathrm{a}}$, Rafi Melnick ${ }^{\mathrm{b}}$ and Dieter Nautz ${ }^{\mathrm{a} *}$ \\ ${ }^{a}$ Freie Universität Berlin, ${ }^{\mathrm{b}}$ The Interdisciplinary Center, IDC Herzliya,
}

\section{This version:}

May 22, 2015

Well-anchored inflation expectations have become a key indicator for the credibility of a central bank's inflation target. Since the outbreak of the recent financial crisis, the existence and the degree of de-anchoring of U.S. inflation expectations have been under debate. This paper introduces an encompassing time-varying parameter model to analyze the changing degree of U.S. inflation expectations anchoring. We confirm that inflation expectations have been partially de-anchored during the financial crisis. Yet, our results suggest that inflation expectations have been successfully reanchored ever since.

Keywords: Anchoring of Inflation Expectations, Financial Crisis, Break-Even Inflation Rates, Time-Varying Parameter

JEL classification: E31, E52, E58, C22

\footnotetext{
*We are grateful for comments and suggestions received from Reint E. Gropp, Oliver Holtemöller and Lars Winkelmann. Financial support from the Deutsche Forschungsgemeinschaft (DFG) through CRC 649 "Economic Risk" is gratefully acknowledged.

E-mail: till.strohsal@fu-berlin.de; melnick@idc.ac.il; dieter.nautz@fu-berlin.de; Phone: +49 (0)30 838-53399 (Till Strohsal).
} 


\section{Introduction}

Inflation expectations have become a major source of information about the credibility of a central bank and the appropriateness of its monetary policy stance. Anchoring inflation expectations at a level compatible with the central bank's inflation target is of particular importance. Central banks increasingly justify and explain their policy decisions based on the need to maintain well-anchored inflation expectations. Since the outbreak of the recent financial crisis, the (de-)anchoring of U.S. inflation expectations has been under debate. Empirical results range from perfect anchoring with no crisis-effect, to a severe and persistent crisis-driven de-anchoring. The aim of the current paper is to reconcile the mixed evidence and to shed new light on the time-varying degree of anchorage of U.S. inflation expectations.

The empirical literature on the anchoring of inflation expectations is divided into two groups. The first strand of literature focuses on the level and the dynamics of inflation and inflation expectations. If deviations from the inflation target are small and short-lived, inflation expectations are seen as wellanchored, see e.g. Mehrotra and Yetman (2014) and Strohsal and Winkelmann (2015). Specifically, when inflation expectations are well-anchored, the expectations should not depend on observed rates of inflation but only on the inflation target. According to Bomfim and Rudebusch (2000), a significant impact of inflation on long-term inflation expectations would indicate a lack of credibility and a de-anchoring of expectations. Demertzis et al. (2012) conclude that U.S. long-term inflation expectations have been well-anchored in recent years, 
including the financial crisis, because they find that inflation expectations were not significantly affected by lagged rates of inflation.

Transitory economic developments with no implications for the long run may affect short-term but should not have any impact on well-anchored longterm inflation expectations. Therefore, a second strand of literature investigates how long-term inflation expectations respond to macroeconomic news (Beechey and Wright, 2009, Gürkaynak et al., 2010a, Beechey et al., 2011) and short-term inflation expectations (Jochmann et al., 2010). For the Euro area, Ehrmann et al. (2011) show that the introduction of the Euro led to a substantial increase in the anchoring of long-term inflation expectations in the pre-crisis period, particularly in Italy and Spain. For the U.S., more recent contributions focusing on the effect of macroeconomic news suggest a de-anchoring of expectations since the outbreak of the financial crisis, see Galati et al. (2011) and Autrup and Grothe (2014). According to the results of multiple endogenous break tests provided by Nautz and Strohsal (2015), U.S. inflation expectations have not been re-anchored ever since.

In view of the contradictory results on the anchoring of U.S. inflation expectations, the current paper offers two contributions. First, so far, empirical studies have either accounted for the impact of lagged rates of inflation or for the role of news-driven short-term expectations. To the best of our knowledge, there is no paper considering both criteria jointly to assess the anchoring of inflation expectations. To avoid possibly misleading conclusions caused by ignoring an important source of de-anchoring, we combine the existing approaches to obtain a more complete picture of the determinants of long-term inflation expectations. 
Second, there is clear evidence that the degree of anchorage changes over time. Yet, irrespective of the strand of literature, empirical studies tend to assume an intrinsically constant degree of inflation expectations anchoring. Typically, the degree of anchorage is only allowed to have a sudden change in response to a regime shift. Jumps in the degree of anchorage are, however, not always a plausible description of monetary policy and of the dynamics of inflation expectations. In many situations, it seems more realistic to assume that the de- and re-anchoring of inflation expectations is continuously evolving. Note that constant parameter models with regime shifts can both under- and overestimate the empirical relevance of de-anchored inflation expectations. Suppose, for example, there is a brief but probably disconcerting period of de-anchoring. In this case, a constant parameter model with endogenous regime shifts would either ignore the threat of de-anchoring completely if the critical period is too short to be detected, or if the de-anchoring is sufficiently strong the model will produce an extended period of de-anchoring that exaggerates the problem. Therefore, in line with Demertzis et al. (2012), our empirical analysis is based on a time-varying parameter model of inflation expectations.

Our results confirm that U.S. long-term inflation expectations have been almost perfectly anchored since 2004. The only exception is the end of 2008 where the anchoring-parameter drops substantially below the value implied by perfect anchoring. This explains why constant parameter models with endogenous breaks tend to produce evidence in favor of an extended deanchoring period. Our results also clearly demonstrate that U.S. inflation ex- 
pectations only respond to short-term expectations and not to lagged inflation rates. This may explain why studies that exclusively focus on the de-anchoring potential of lagged inflation rates tend to underestimate the credibility problems of monetary policy stirred by the financial crisis.

The rest of the paper is structured as follows. Section 2 discusses the determinants of inflation expectations and introduces the time-varying parameter model of expectations anchoring. The data are presented in Section 3. Section 4 shows the empirical results. Finally, Section 5 offers some concluding remarks.

\section{An Empirical Model of Inflation Expectations}

\subsection{Determinants of Long-Term Inflation Expectations}

The Inflation Target A minimum requirement for effective central bank communication is that inflation expectations are - at least to some extent guided by the central bank's inflation target $\pi^{*}$. In many countries, the announcement of inflation targets may have contributed to lower inflation rates, see Johnson (2003). However, inflation targets do not have to be officially announced to be effective. Many central banks, including the ECB and the U.S. Federal Reserve, do not publish official inflation targets (as the Bank of England does) but are nevertheless able to communicate the level of their longterm inflation objective to the markets. Over the last decades, it has become increasingly obvious that the Fed's long-run inflation target is very much in 
line with other central banks that focus on price-stability. In the following, we assume that the Fed's inflation target is constant at $2 \%$ in our sample period, i.e. from 2004 onwards 1

The more credible the central bank's inflation target, the larger its role in expectations formation and, thus, the degree of anchorage of inflation expectations. In the limiting case of perfect anchorage, the inflation target should be the only relevant determinant of inflation expectations. In this case, any deviation of inflation from the target is seen as short-lived because markets are convinced that the central bank is able and willing to bring inflation back to target quickly. As a consequence, long-term inflation expectations $\pi_{l}^{e}$ should remain particularly close to the target.

Past Inflation Unfortunately, the anchoring of inflation expectations might not always be perfect. The literature offers a number of explanations why inflation expectations may depend not only on the target for current and future inflation but also on the central bank's past inflation performance. If the credibility of the central bank's inflation target is imperfect, expectations formation incorporates learning from lagged inflation values, see e.g. Orphanides and Williams (2005). Therefore, in accordance with Bomfim and Rudebusch (2000), a significant impact of lagged inflation on long-term inflation expectations can be interpreted as lack of credibility and de-anchoring of inflation expectations.

\footnotetext{
${ }^{1}$ Since 2012, the Fed's implicit inflation target has been clearly communicated via the publication of dot projections. In these projections, the board members report their individual views on the central tendency and range of future output growth, unemployment and inflation. Interestingly, the reported value of the long-run inflation rate is always $2 \%$. In sharp contrast to the projections for output and employment, the long-run projection for inflation neither varies over time nor across board members.
} 
Short-Term Inflation Expectations Movements of short-term inflation expectations, $\pi_{s}^{e}$, do not necessarily imply weak credibility of the central bank's target and de-anchoring of long-term inflation expectations. In fact, there is clear evidence that short-term inflation expectations significantly respond to economic surprises stirred by the announcement of macroeconomic variables, see Beechey et al. (2011), Autrup and Grothe (2014), Netšunajev and Winkelmann (2015) and the references therein. Well-anchored long-term inflation expectations, however, should not be affected by temporary shocks or transitory economic developments with no implications for the long run. A second criterion for the anchoring of inflation expectations is therefore the extent to which news-driven short-term inflation expectations feed into longer-term expectations, see Jochmann et al. (2010). If expectations are well-anchored, short-term expectations should not play a significant role in the formation of long-term inflation expectations.

\section{2. (De-)Anchoring of Inflation Expectations}

To obtain a more complete picture of the determinants of inflation expectations, we combine the existing approaches to analyze expectations anchoring. Building on Bomfim and Rudebusch (2000), we start with an equation where long-term inflation expectations $\pi_{l, t}^{e}$ are a weighted average of the inflation target $\pi^{*}$, lagged inflation $\pi_{t-1}$, and news-driven short-term inflation expectations $\pi_{s, t-1}^{e}$ :

$$
\pi_{l, t}^{e}=\left(1-\theta_{1}-\theta_{2}\right) \pi^{*}+\theta_{1} \pi_{t-1}+\theta_{2} \pi_{s, t-1}^{e}
$$


When $\theta_{2}=0$, short-term expectations play no role and inflation expectations only depend on the inflation target and lagged inflation. When $\theta_{1}=0$, the impact of lagged inflation on the formation of long-term expectations can be ignored. Note that inflation expectations are perfectly anchored if $\theta_{1}=\theta_{2}=0$ which implies that $\pi_{l, t}^{e}=\pi^{*}$. Since we are particularly interested in the dynamics of inflation anchoring, we re-arrange the static level relation by subtracting $\pi_{l, t}^{e}$ from both sides of equation (1) to obtain a dynamic adjustment equation of long-term inflation expectations:

$$
\Delta \pi_{l, t}^{e}=\left(1-\theta_{1}-\theta_{2}\right)\left(\pi^{*}-\pi_{l, t-1}^{e}\right)+\theta_{1}\left(\pi_{t-1}-\pi_{l, t-1}^{e}\right)+\theta_{2}\left(\pi_{s, t-1}^{e}-\pi_{l, t-1}^{e}\right) .
$$

This equation is easy to interpret and a straightforward generalization of the existing approaches employed in the empirical literature on inflation expectations anchoring. De-anchored long-term inflation expectations may follow actual inflation $\left(\theta_{1}>0\right)$, or news-driven short-term inflation expectations $\left(\theta_{2}>0\right)$. Put differently, the overall degree of anchoring and the speed of adjustment of long-term expectations to the target $\left(1-\theta_{1}-\theta_{2}\right)$ is greater when the total impact of both sources of de-anchoring $\left(\theta_{1}+\theta_{2}\right)$ is small. Estimating the adjustment coefficients $\theta_{1}$ and $\theta_{2}$ reveals the relative importance of the sources of de-anchoring. Note that $1-\theta_{1}-\theta_{2}$ can be interpreted as the degree of anchorage of inflation expectations. 


\subsection{Assessing the (De-)Anchoring of Inflation Expectations Across Time}

Central bank credibility can be gained, but it also can be lost. As a consequence, the degree of inflation expectations anchoring might not be constant over time. The history of inflation in the U.S. clearly suggests that the degree of anchorage was lower during the Great Inflation of the sixties and seventies, than during the Great Moderation that ended with the outbreak of the recent financial crisis. The impact of the financial crisis and related monetary policy on the degree of anchorage is, however, less obvious. So far, the standard approach of the empirical literature to account for time-varying anchoring is simply to split the sample and to estimate a separate constant parameter model for each of the sub-samples, see e.g. Galati et al. (2011) and Autrup and Grothe (2014). Nautz and Strohsal (2015) employ multiple endogenous break point tests to demonstrate that U.S. long-term inflation expectations respond to news and were, therefore, de-anchored by the crisis. Since there is no second break detected, they conclude that expectations have not been re-anchored ever since.

However, estimating the time-varying degree of inflation expectations anchoring using regime-dependent constant parameter models is not without problems. First, constant parameter models with regime-shifts assume that the intrinsically constant degree of anchorage suddenly changes to a new value. However, regaining central bank credibility and re-anchoring inflation expectations might be a long and painful process where the degree of anchorage 
rises continuously over time. Particular in turbulent times, monetary policy requires a more flexible measure of expectations anchoring. Second, constant parameter models with endogenous break point tests require a minimum number of observations in each regime. For example, Nautz and Strohsal (2015) have to assume a minimum regime length of 6 months. As a consequence, this model is not designed to reveal shorter de-anchoring periods. Apparently, this inflexibility of constant parameter models may produce misleading results. Suppose, for example, the central bank responds quickly to a drop in the degree of anchorage and is able to re-anchor inflation expectations over the next few months. Although this scenario might be a realistic description of monetary policy in the aftermath of the Lehman crash, it cannot be captured by constant parameter models. In an empirical application, constant parameter models will either ignore the de-anchoring episode completely (because the risky de-anchoring period is less than 6 months) and therefore underestimate the danger of de-anchored inflation expectations, or the models will produce an extended but spurious period of de-anchoring that exaggerates the credibility problem of the central bank.

The natural solution to the above problems is a time-varying parameter (TVP) approach. Therefore, we adopt the standard TVP model representation (see Appendix A) to the constant parameter model for inflation expectations introduced in the previous section. Specifically, our empirical analysis of the time-varying degree of inflation expectations anchoring will be based on the 
following model:

$$
\Delta \pi_{l, t}^{e}=\left(1-\theta_{1 t}-\theta_{2 t}\right)\left(\pi^{*}-\pi_{l, t-1}^{e}\right)+\theta_{1 t}\left(\pi_{t-1}-\pi_{l, t-1}^{e}\right)+\theta_{2 t}\left(\pi_{s, t-1}^{e}-\pi_{l, t-1}^{e}\right) .
$$

Note that the time-varying de-anchoring parameters $\theta_{1 t}$ and $\theta_{2 t}$ provide the information to which extent past inflation or short-term expectations are responsible for the deviation of long-term inflation expectations from the inflation target. Accordingly, the anchoring parameter, $1-\theta_{t 1}-\theta_{t 2}$, is also time-varying and, multiplied by 100, may be interpreted as the percentage at which expectations are anchored in period $t$. Since we additionally account for de-anchoring due to short-term expectations, our measure of the degree of inflation expectations anchoring generalizes the credibility proxy introduced by Demertzis et al. (2012).

\section{Data}

Inflation-linked securities have become an increasingly important source of information about expected inflation. Yields of index-linked and nominal bonds with equal maturities are used to derive the break-even inflation (BEI) rate, i.e., the rate of inflation at which the payoff of the two types of bonds is equal. In contrast to quarterly or even semi-annual surveys of expected inflation, BEI rates are readily available at high frequency and are therefore particularly suitable to investigate and monitor the time-varying dynamics of inflation expectations. The degree of inflation expectations anchoring is primarily reflected in 
longer-term expectations. In the following, we consider one-year forward rates ending 10 and 5 years ahead, respectively, which have become standard indicators of long- and medium-term inflation expectations, see e.g. Gürkaynak et al. (2010a) and Galati et al. (2011). For short-term inflation expectations, we employ the shortest horizon available which is the one-year forward rate ending 3 years ahead. ${ }^{2}$

Constant maturity series of BEI rates are available from Federal Reserve Board staff calculations, cf. Gürkaynak et al. (2010b). Our sample covers monthly observations from 2004M1 to 2014M12. We start in 2004 to ensure availability of enough index-linked bonds to estimate real yield curves, see e.g. Gürkaynak et al. (2010b). Inflation is measured by the annual percentage change of the consumer price index. The data of expected and actual inflation are depicted in Figure1.

The main problem of market based inflation measures is that risk and liquidity conditions may distort the pricing of nominal and inflation-linked bonds. For example, a higher trading volume in inflation-linked bonds may increase the break-even inflation rate only because it reduces the liquidity premium on inflation-linked bonds and, thereby, lowers the real yield. In line with e.g. Gürkaynak et al. (2010a), we account for this problem by including common measures of liquidity and risk as additional controls in the empirical version of equation (3). These measures include the relative trading volume of inflation-indexed bonds with respect to the total trading volume of

\footnotetext{
${ }^{2}$ An alternative candidate for short-term expectations is the two-year spot rate. Note, however, that our main results do not depend on that choice.
} 
Figure 1 Forward Break-Even Inflation Rates and Actual Inflation

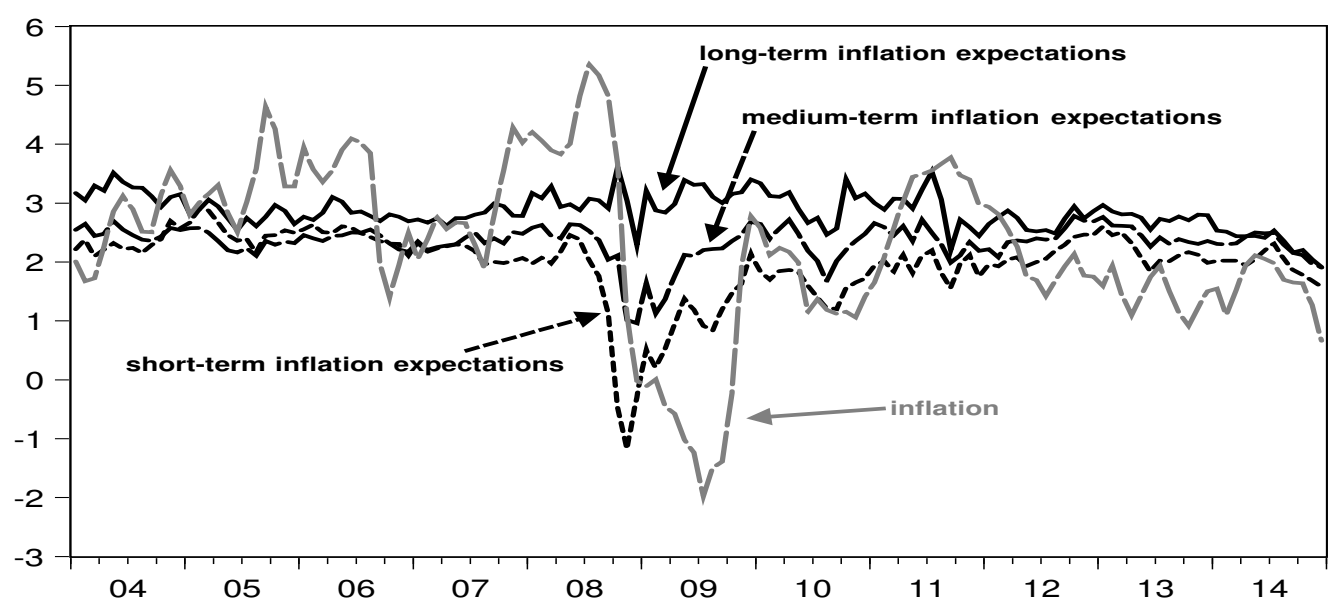

Notes: The figure shows the yearly inflation rate (dashed gray line), long-term inflation expectations measured as 1-year break-even forward rate ending in 10 years (solid black line), medium-term inflation expectations measured as 1-year break-even forward rate ending in 5 years (dashed black line) and short-term inflation expectations measured as 1-year break-even forward rate ending in 3 years (dotted black line).

nominal and real bonds which is taken from the Federal Reserve Bank of New York. The CBOE stock option price volatility index, VIX, and Moody's AAA corporate bond spread can be obtained from the Federal Reserve Bank of St. Louis. We also included the policy uncertainty index provided by http://policyuncertainty.com. 


\section{What Drives Inflation Expectations?}

\subsection{Inflation Expectations Anchoring: Results from a Constant Parameter Model}

In a first step, we assume that the degree of inflation expectations anchoring is constant during the sample period, i.e. from 2004 until the end of 2014. Table 1 summarizes the estimation results for the constant parameter model (2) governing the formation of long- and medium-term inflation expectations. The estimated coefficient corresponding to lagged inflation $\left(\theta_{1}\right)$ is economically small and far from being significant for both expectations horizons. In accordance with Demertzis et al. (2012), this shows that lagged inflation rates have not been a significant source of de-anchoring for U.S. long-term inflation expectations.

However, this is not the whole story. In particular, irrespective of the expectation horizon, the estimated coefficient of short-term expectations $\left(\theta_{2}\right)$ is statistically significant and plausibly signed. Accordingly, the constant parameter model provides evidence against perfectly anchored inflation expectations. The model suggests that the degree of anchorage has been $79 \%$ for long-term and about $64 \%$ for medium-term inflation expectations in each month from 2004 onwards. Thus, as expected, medium-term expectations are less anchored than longer-term expectations. This is also reflected in the test for joint significance of $\theta_{1}$ and $\theta_{2}$, see Table 1 . 
Table 1 Constant Parameter Model: The (De-)Anchoring of U.S. Inflation Expectations

\begin{tabular}{c|cc|c}
$\begin{array}{c}\text { expectations } \\
\text { horizon }\end{array}$ & $\begin{array}{c}\text { past } \\
\text { inflation } \\
\theta_{1}\end{array}$ & $\begin{array}{c}\text { short-term } \\
\text { inflation expectations } \\
\theta_{2}\end{array}$ & $\begin{array}{c}\text { joint } \\
\text { test } \\
\theta_{1}=\theta_{2}=0\end{array}$ \\
\hline 10 years & -0.020 & $\mathbf{0 . 2 0 8}$ & $\mathbf{2 . 3 9 0}$ \\
& $(0.489)$ & $(\mathbf{0 . 0 3 9})$ & $(\mathbf{0 . 0 9 6})$ \\
5 years & -0.003 & $\mathbf{0 . 3 5 7}$ & $\mathbf{1 9 . 6 4 0}$ \\
& $(0.900)$ & $(\mathbf{0 . 0 0 0})$ & $(\mathbf{0 . 0 0 0 )}$ \\
\hline \hline
\end{tabular}

Notes: The table shows the estimation results from the empirical version of equation (2) over the sample 2004M01 - 2014M12. Significance tests are based on Newey-West heteroskedasticity and autocorrelation consistent standard errors with automatic bandwidth selection. Values in parentheses below coefficients are $p$-values. The joint test has the null hypothesis that the effects of past inflation and short-term inflation expectations are both zero. Regressions include control variables for risk and a constant term.

The assumption of a time-invariant degree of inflation expectations anchoring is hard to defend, particularly in view of the increased uncertainty during the financial crisis. In the next section, we therefore estimate the time-varyingparameter version of the inflation expectations adjustment equation.

\subsection{Inflation Expectations Anchoring: Results from a Time-Varying Parameter Model}

Let us now turn to the time-varying parameter model (3) of inflation expectations anchoring. We estimate the model by maximum likelihood using the Kalman filter. The state space form of the model and the complete set of results are given in Appendix $\mathrm{A}$ 
Figure 2 and Figure 3 report the (smoothed) estimates of the time-varying (de-)anchoring parameters $\theta_{1 t}, \theta_{2 t}$, and $1-\theta_{1 t}-\theta_{2 t}$ obtained for long- and medium-term inflation expectations, respectively. For long-term expectations, the time-varying estimates of the anchoring-parameter, $1-\theta_{1 t}-\theta_{2 t}$, are almost never significantly different from one. As a result, the hypothesis of perfect expectations anchoring cannot be rejected by the data. In fact, the estimated average degree of anchorage is $95 \%$ which is very close to perfect anchoring. The only exception is December 2008 where the anchoring-parameter is significantly below one (73\%) implying that anchoring was imperfect (but nevertheless well above zero) shortly after the Lehman breakdown. The middle and lower part of Figure 2 reveal the sources of that brief period of de-anchoring. In line with our results obtained for the constant parameter model, the only significant source of de-anchored long-term inflation expectations are movements of short-term inflation expectations. The corresponding estimate $\theta_{2 t}$ is significantly greater than zero exactly in December 2008. By contrast, the results obtained for $\theta_{1 t}$ demonstrate that long-term inflation expectations have never responded significantly to lagged inflation. Another noteworthy result is visible at the very end of our sample period. Note that there is a disconcerting (but statistically insignificant) decline in the anchoring-parameter from 2013 onwards. 
Figure 2 Anchoring-Percentage and De-Anchoring Sources of 10-Year Inflation Expectations
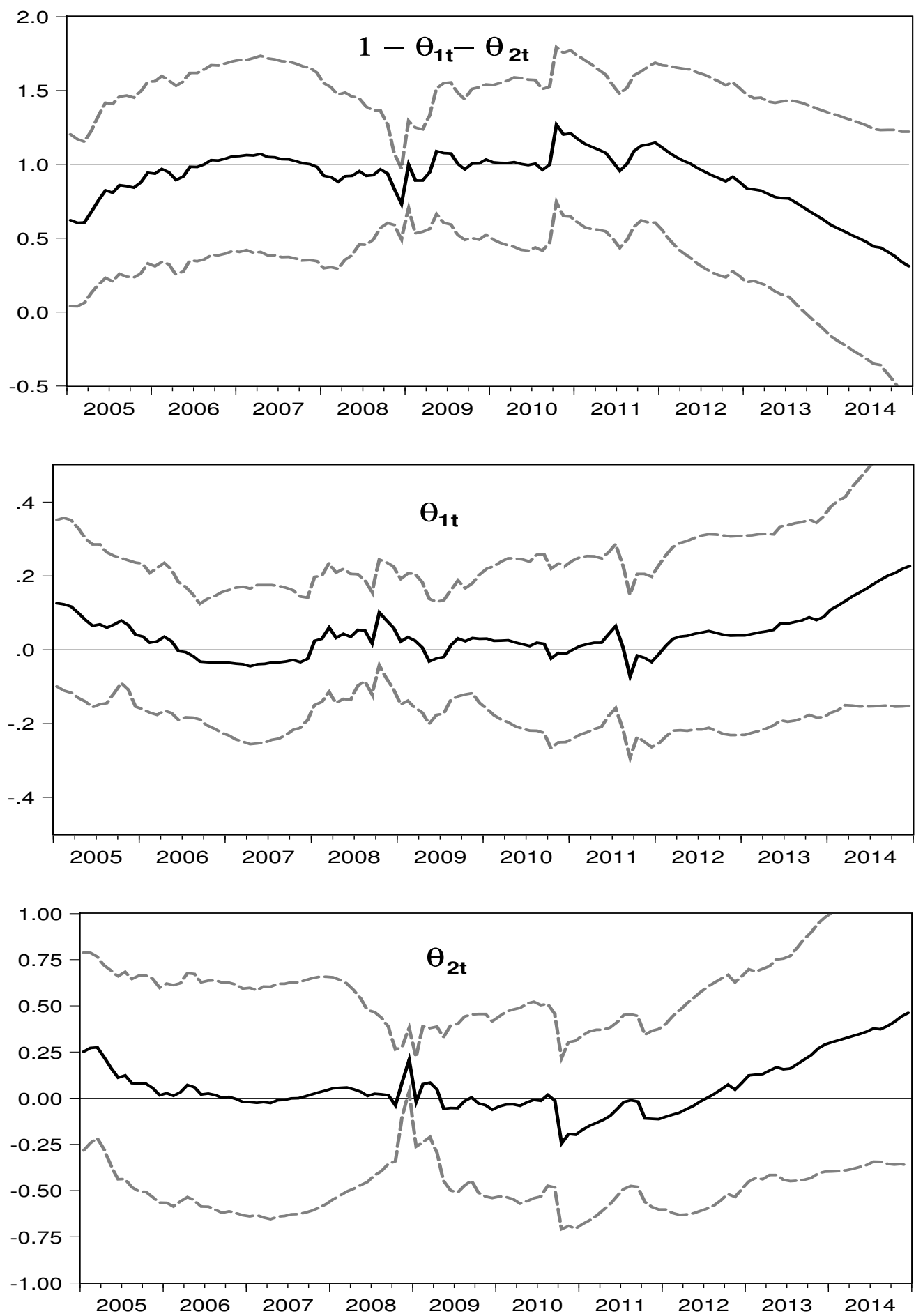

Notes: The figure refers to 10-year inflation expectations and shows the estimated anchoring parameter $1-\theta_{1 t}-\theta_{2 t}$ (top figure), the adjustment to past inflation $\theta_{1 t}$ (middle figure) and the adjustment to short-term inflation expectations $\theta_{2 t}$ (bottom figure) as solid black lines and the $95 \%$ confidence interval as dashed gray lines; cf. model (3). 
Figure 3 Anchoring-Percentage and De-Anchoring Sources of 5-Year Inflation Expectations
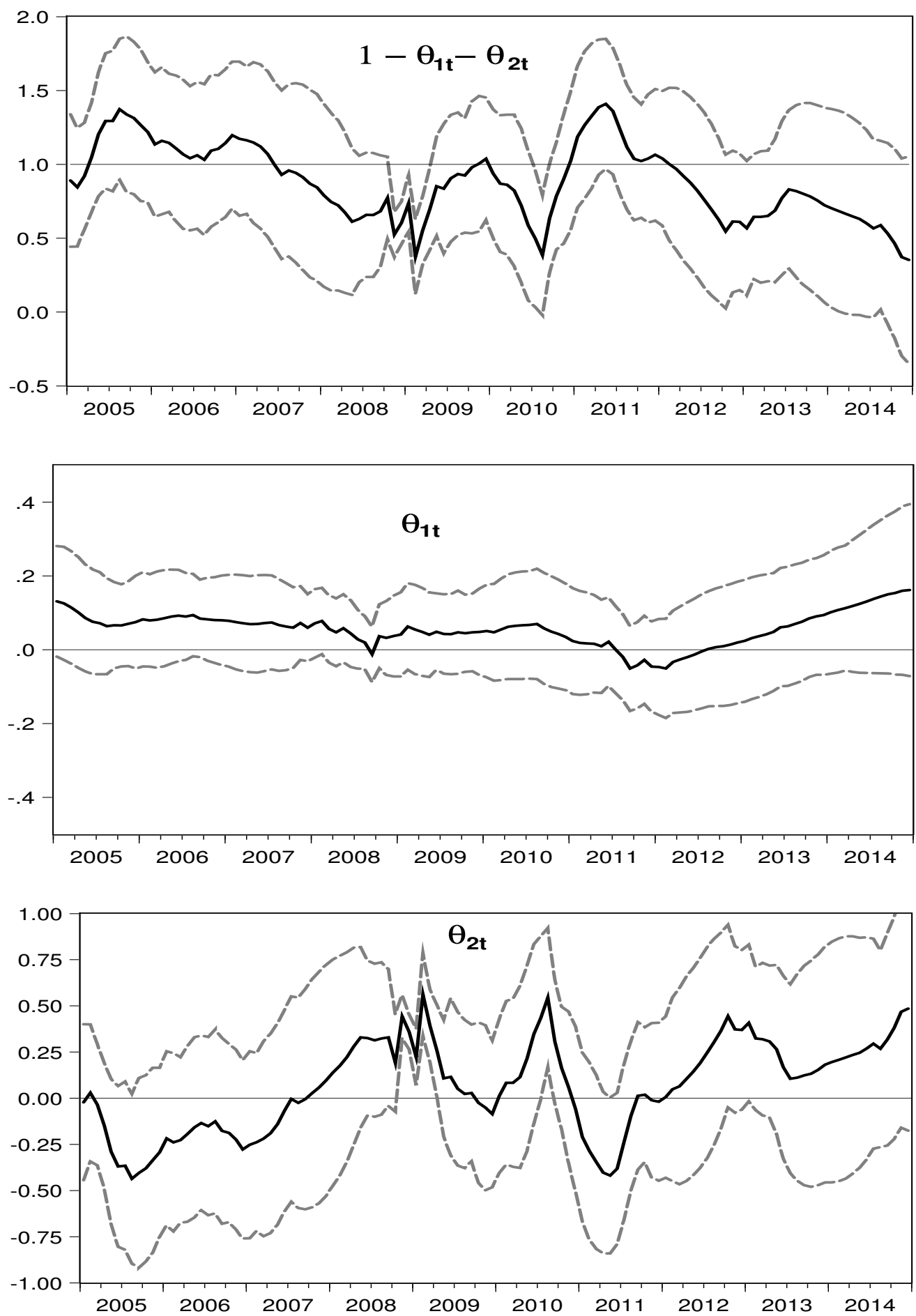

Notes: The figure refers to 5 -year inflation expectations and shows the estimated anchoring parameter $1-\theta_{1 t}-\theta_{2 t}$ (top figure), the adjustment to past inflation $\theta_{1 t}$ (middle figure) and the adjustment to short-term inflation expectations $\theta_{2 t}$ (bottom figure) as solid black lines and the $95 \%$ confidence interval as dashed gray lines; cf. model (3). 
In line with the literature, the time-varying parameter model confirms that medium-term inflation expectations are typically less anchored than long-term expectations. On the one hand, as can be seen from Table 2, the average anchoring-parameter is only $87 \%$. On the other hand, Figure 3 shows that

Table 2 Time-Varying degree of anchorage of U.S. Inflation Expectations

\begin{tabular}{c|cc|cc|c}
$\begin{array}{c}\text { expectations } \\
\text { horizon }\end{array}$ & de-anchoring & minimal anchoring & \multicolumn{2}{|c|}{ response to } & average degree \\
periods & percentage & $\pi_{t-1}$ & $\pi_{s, t-1}^{e}$ & of anchorage \\
\hline 10 years & $2008 \mathrm{M} 12$ & $73 \%$ at 2008M12 & no & yes & $95 \%$ \\
5 years & $2008 \mathrm{M} 10-2009 \mathrm{M} 04$ & $38 \%$ at 2009M02 & no & yes & $87 \%$ \\
& $2010 \mathrm{M} 07-2010 \mathrm{M} 09$ & $39 \%$ at 2009M08 & & & \\
\hline \hline
\end{tabular}

Notes: De-anchoring periods represent periods where the anchoring parameter $1-\theta_{1 t}-\theta_{2 t}$ in equation (3) is significantly below 1 at the $5 \%$-level. Minimal anchoring percentage denotes the minimum point estimate of $1-\theta_{1 t}-\theta_{2 t}$ and indicates the severity of de-anchoring. A response to past inflation or short-term expectations shows the source of de-anchoring. The last column includes information on the direction of the anchoring parameter towards the end of the sample. The complete set of results is given in Appendix B

medium-term expectations experienced even two periods of de-anchoring. The first period, from 2008M10 until 2009M04, is related to the Lehman breakdown. During this relatively long period, the estimated degree of anchorage reached a minimum value of only $38 \%$. In the second period of de-anchored medium-term expectations, running from 2010M07 until 2010M09, the degree of anchorage decreases again to $39 \%$ but recovers more quickly. Similar to the behavior of long-term expectations, there seems to be a tendency of deanchoring for medium-term inflation expectations from 2013 onwards. Results for long- and medium-term expectations do agree with respect to the sources of de-anchoring. Both de-anchoring episodes are completely driven by 
forward-looking short-term expectations and not by backward-looking lagged inflation.

Our main findings on the (de-)anchoring of U.S. inflation expectations are summarized in Table 2. The results show the benefits of a comprehensive and flexible approach to estimating the degree of expectations anchoring. Using a time-varying parameter model and considering both sources of de-anchoring jointly, our findings may reconcile the mixed evidence regarding inflation expectations anchoring in the U.S. On the one hand, the brief but nevertheless significant period of de-anchored inflation expectations stirred by the outbreak of the financial crisis confirms recent evidence on de-anchoring provided by studies relying on regressions with constant parameters, cf. Nautz and Strohsal (2015). In contrast to constant parameter models with regime-shifts, the more flexible time-varying parameter approach is able to detect that monetary policy re-anchored inflation expectations rather quickly. On the other hand, even if a time-varying model is applied, the danger of de-anchored inflation expectations can be underestimated if one of the two sources of deanchoring is neglected, see Demertzis et al. (2012).

\section{Conclusions}

Long-term inflation expectations have become a key indicator for the effectiveness of monetary policy. Specifically, long-term inflation expectations should be well-anchored. That is, they should only depend on the central bank's infla- 
tion target and should not be affected by (i) lagged inflation rates or (ii) movements of short-term inflation expectations. The current paper provides new evidence on the anchoring of U.S. long-term inflation expectations in the aftermath of the recent financial crisis. The contribution of this paper is twofold. First, while the literature typically restricts its attention to only one of the above criteria of de-anchoring, we account for both criteria and obtain a more complete picture of the determinants of inflation expectations. Second, building on Demertzis et al. (2012), we estimate the changing degree of anchoring using a time-varying parameter model of inflation expectations. The major advantage of this model is that it avoids the often implausible assumption of sudden regime shifts.

Our results show that U.S. long-term inflation expectations are almost perfectly anchored from 2004 onwards. This does not imply, however, that maintaining anchored inflation expectations has not been an issue. In fact, the time-varying parameter model detects a brief period at the end of 2008, where the estimated anchoring-parameter is significantly below the value implied by perfect anchoring. This remarkable finding is strong evidence that the credibility of the Federal Reserve's inflation target was challenged by the aggressive monetary policy introduced to deal with the financial crisis and the following additional rounds of quantitative easing. According to our estimates, however, the credibility of monetary policy was quickly restored, indicating that the financial crisis had no lasting effect for the anchorage of U.S. inflation expectations. 


\section{A. The TVP Model in State Space Form}

For estimation purposes, we cast the time-varying parameter model for inflation expectations

$$
\begin{gathered}
\Delta \pi_{l, t}^{e}=\left(1-\theta_{1 t}-\theta_{2 t}\right)\left(\pi^{*}-\pi_{l, t-1}^{e}\right)+\theta_{1 t}\left(\pi_{t-1}-\pi_{l, t-1}^{e}\right)+\theta_{2 t}\left(\pi_{s, t-1}^{e}-\pi_{l, t-1}^{e}\right)+\beta X_{t}+u_{t} \\
\theta_{1 t}=\theta_{1 t-1}+\varepsilon_{1 t} \\
\theta_{2 t}=\theta_{2 t-1}+\varepsilon_{2 t} \\
u_{t}=\alpha_{0}+\alpha_{1} u_{t-1}+v_{t}
\end{gathered}
$$

in state space form as follows

$$
\begin{gathered}
\Delta \pi_{l, t}^{e}=c_{t}+Z_{t} \Theta_{t} \\
\Theta_{t}=d+T \Theta_{t-1}+V_{t}
\end{gathered}
$$

with $Z_{t}=\left(\begin{array}{lll}\pi_{t-1}-\pi^{T} & \pi_{s, t-1}^{e}-\pi^{T} & 1\end{array}\right), \Theta_{t}=\left(\begin{array}{lll}\theta_{1 t} & \theta_{2 t} & u_{t}\end{array}\right)^{\prime}, c_{t}=\pi^{T}-\pi_{l, t}^{e}+\beta X_{t}$, $d=\left(\begin{array}{lll}0 & 0 & \alpha_{0}\end{array}\right), T=\left(\begin{array}{ccc}1 & 0 & 0 \\ 0 & 1 & 0 \\ 0 & 0 & \alpha_{1}\end{array}\right), V_{t}=\left(\begin{array}{lll}\varepsilon_{1 t} & \varepsilon_{2 t} & v_{t}\end{array}\right)$ and variance-covariance matrix $\Sigma=\operatorname{Var}\left(V_{t}\right)=\operatorname{diag}\left(\exp \left(\sigma_{\varepsilon_{1}}^{2}\right) \exp \left(\sigma_{\varepsilon_{2}}^{2}\right) \exp \left(\sigma_{v}^{2}\right)\right)$.

During estimation the variances parameters are expressed in exponential form to ensure that the variances themselves are positive. We use the Kalman filter to compute the one-step ahead estimates of the means and variances of the states. The parameters $\gamma$ are estimated by maximizing the Gaussian log- 
likelihood

$$
\ell(\gamma)=-\frac{T}{2} \ln 2 \pi-\frac{1}{2} \sum_{t=1}^{T} \ln \left|F_{t}(\gamma)\right|-\frac{1}{2} \sum_{t=1}^{T} e_{t}^{\prime}(\gamma) F_{t}(\gamma)^{-1} e_{t}(\gamma)
$$

where $e_{t}=\Delta \pi_{t}^{e}-\mathrm{E}\left(\Delta \pi_{t}^{e} \mid I_{t-1}\right)$ and $F_{t}=\operatorname{Var}\left(e_{t} \mid I_{t-1}\right)$ are the one-step ahead forecast error and its variance. The information set $I_{t-1}$ contains all information available up to time $t$.

\section{B. Complete Set of Estimation Results}

We used the optimization algorithm of Berndt et al.(1974) to evaluate the likelihood. Convergence and parameter estimates remain almost unchanged when using other algorithms. The results presented in Table 3 imply that there is significant time variation of the parameters $\theta_{1 t}$ and $\theta_{2 t}$. The Q-statistics indicate that almost no autocorrelation is left in the estimated forecast errors implying that the model is flexible enough to capture the dynamics of the underlying time series sufficiently well. 
Table 3 Parameter Estimates and Diagnostic Tests for the TVP Model

\begin{tabular}{|c|c|c|c|c|c|}
\hline \multicolumn{2}{|c|}{ expectations } & \multicolumn{4}{|c|}{ estimated parameters } \\
\hline horizon & $\sigma_{\varepsilon_{1}}^{2}$ & $\sigma_{\varepsilon_{2}}^{2}$ & $\sigma_{v}^{2}$ & $\alpha_{0}$ & $\alpha_{1}$ \\
\hline \multirow[t]{6}{*}{10 years } & $\begin{array}{c}-5.84^{* * *} \\
{[0.79]}\end{array}$ & $\begin{array}{c}-4.10^{* * *} \\
{[0.54]}\end{array}$ & $\begin{array}{c}-3.44^{* * *} \\
{[0.20]}\end{array}$ & $\begin{array}{l}0.15^{* *} \\
{[0.07]}\end{array}$ & $\begin{array}{c}0.78^{* * *} \\
{[0.09]}\end{array}$ \\
\hline & \multicolumn{5}{|c|}{ diagnostics of forecast errors } \\
\hline & & $\mathrm{Q}(1)$ & $\mathrm{Q}(2)$ & $\mathrm{Q}(5)$ & $\mathrm{Q}(10)$ \\
\hline & & 0.68 & 0.14 & 0.16 & 0.34 \\
\hline & & \multicolumn{4}{|c|}{ estimated parameters } \\
\hline & $\sigma_{\varepsilon_{1}}^{2}$ & $\sigma_{\varepsilon_{2}}^{2}$ & $\sigma_{v}^{2}$ & $\alpha_{0}$ & $\alpha_{1}$ \\
\hline \multirow[t]{5}{*}{5 years } & $-6.82^{* * *}$ & $-3.64^{* * *}$ & $-4.43^{* * *}$ & $0.16^{*}$ & $0.63^{* * *}$ \\
\hline & {$[0.84]$} & {$[0.34]$} & {$[0.23]$} & {$[0.10]$} & {$[0.15]$} \\
\hline & & \multicolumn{4}{|c|}{ diagnostics of forecast errors } \\
\hline & & $\mathrm{Q}(1)$ & $\mathrm{Q}(2)$ & $\mathrm{Q}(5)$ & $Q(10)$ \\
\hline & & 0.90 & 0.94 & 0.99 & 0.65 \\
\hline
\end{tabular}

Notes: The table shows the estimated parameters for the model (4) obtained from maximizing (10). Standard errors are given in brackets. ${ }^{*},{ }^{* *}$ and ${ }^{* * *}$ indicate significance at the $10 \%, 5 \%$ and $1 \%$ level, respectively. Variance parameters are in exponential form to ensure positive variances $\left(\exp \left(\sigma_{\varepsilon_{1}}^{2}\right), \exp \left(\sigma_{\varepsilon_{2}}^{2}\right), \exp \left(\sigma_{v}^{2}\right)\right) . \mathrm{Q}(1)$, $\mathrm{Q}(2), \mathrm{Q}(5)$ and $\mathrm{Q}(10)$ represent $p$-values of $\mathrm{Q}$-tests for remaining autocorrelation in the standardized forecast errors. 


\section{References}

Autrup, S. L. and Grothe, M. (2014). Economic surprises and inflation expectations: Has anchoring of expectations survived the crisis? European Central Bank Working Paper Series, 1671.

Beechey, M. J., Johannsen, B. K., and Levin, A. T. (2011). Are long-run inflation expectations anchored more firmly in the Euro area than in the United States? American Economic Journal: Macroeconomics, 3(2):pp. 104-129.

Beechey, M. J. and Wright, J. H. (2009). The high-frequency impact of news on long-term yields and forward rates: Is it real? Journal of Monetary Economics, 56(4):535 - 544 .

Berndt, E. K., Hall, B. H., and Hall, R. E. (1974). Estimation and inference in nonlinear structural models. In Annals of Economic and Social Measurement, Volume 3, number 4, pages 103-116. NBER.

Bomfim, A. N. and Rudebusch, G. D. (2000). Opportunistic and deliberate disinflation under imperfect credibility. Journal of Money, Credit and Banking, 32(4):pp. 707-721.

Demertzis, M., Marcellino, M., and Viegi, N. (2012). A credibility proxy: Tracking US monetary developments. The BE Journal of Macroeconomics, 12(1).

Ehrmann, M., Fratzscher, M., Gürkaynak, R. S., and Swanson, E. T. (2011). Convergence and anchoring of yield curves in the euro area. The Review of Economics and Statistics, 93(1):350-364.

Galati, G., Poelhekke, S., and Zhou, C. (2011). Did the crisis affect inflation expectations? International Journal of Central Banking, 7(1):167-207.

Gürkaynak, R. S., Levin, A., and Swanson, E. (2010a). Does inflation targeting anchor long-run inflation expectations? evidence from the U.S., UK, and Sweden. Journal of the European Economic Association, 8(6):1208-1242.

Gürkaynak, R. S., Sack, B., and Wright, J. H. (2010b). The tips yield curve and inflation compensation. American Economic Journal: Macroeconomics, 2(1):pp. 70-92.

Jochmann, M., Koop, G., and Potter, S. M. (2010). Modeling the dynamics of inflation compensation. Journal of Empirical Finance, 17(1):157 - 167. 
Johnson, D. (2003). The effect of inflation targets on the level of expected inflation in five countries. The Review of Economics and Statistics, 85(4):1076-1081.

Mehrotra, A. N. and Yetman, J. (2014). Decaying expectations: What inflation forecasts tell us about the anchoring of inflation expectations. BIS Working Paper.

Nautz, D. and Strohsal, T. (2015). Are US inflation expectations re-anchored? Economics Letters, 127:6-9.

Netšunajev, A. and Winkelmann, L. (2015). International transmissions of inflation expectations in a Markov switching structural VAR model. SFB 649 Discussion Paper.

Orphanides, A. and Williams, J. C. (2005). Expectations, learning and monetary policy. Journal of Economic Dynamics and Control, 29(11):1807-1808.

Strohsal, T. and Winkelmann, L. (2015). Assessing the anchoring of inflation expectations. Journal of International Money and Finance, 50(0):33 - 48. 


\section{SFB 649 Discussion Paper Series 2015}

For a complete list of Discussion Papers published by the SFB 649, please visit http://sfb649.wiwi.hu-berlin.de.

001 "Pricing Kernel Modeling" by Denis Belomestny, Shujie Ma and Wolfgang Karl Härdle, January 2015.

002 "Estimating the Value of Urban Green Space: A hedonic Pricing Analysis of the Housing Market in Cologne, Germany" by Jens Kolbe and Henry Wüstemann, January 2015.

003 "Identifying Berlin's land value map using Adaptive Weights Smoothing" by Jens Kolbe, Rainer Schulz, Martin Wersing and Axel Werwatz, January 2015.

004 "Efficiency of Wind Power Production and its Determinants" by Simone Pieralli, Matthias Ritter and Martin Odening, January 2015.

005 "Distillation of News Flow into Analysis of Stock Reactions" by Junni L. Zhang, Wolfgang K. Härdle, Cathy Y. Chen and Elisabeth Bommes, January 2015.

006 "Cognitive Bubbles" by Ciril Bosch-Rosay, Thomas Meissnerz and Antoni Bosch-Domènech, February 2015.

007 "Stochastic Population Analysis: A Functional Data Approach" by Lei Fang and Wolfgang K. Härdle, February 2015.

008 "Nonparametric change-point analysis of volatility" by Markus Bibinger, Moritz Jirak and Mathias Vetter, February 2015.

009 "From Galloping Inflation to Price Stability in Steps: Israel 1985-2013" by Rafi Melnick and till Strohsal, February 2015.

010 "Estimation of NAIRU with Inflation Expectation Data" by Wei Cui, Wolfgang K. Härdle and Weining Wang, February 2015.

011 "Competitors In Merger Control: Shall They Be Merely Heard Or Also Listened To?" by Thomas Giebe and Miyu Lee, February 2015.

012 "The Impact of Credit Default Swap Trading on Loan Syndication" by Daniel Streitz, March 2015.

013 "Pitfalls and Perils of Financial Innovation: The Use of CDS by Corporate Bond Funds" by Tim Adam and Andre Guettler, March 2015.

014 "Generalized Exogenous Processes in DSGE: A Bayesian Approach" by Alexander Meyer-Gohde and Daniel Neuhoff, March 2015.

015 "Structural Vector Autoregressions with Heteroskedasticy" by Helmut Lütkepohl and Aleksei Netšunajev, March 2015.

016 "Testing Missing at Random using Instrumental Variables" by Christoph Breunig, March 2015.

017 "Loss Potential and Disclosures Related to Credit Derivatives - A CrossCountry Comparison of Corporate Bond Funds under U.S. and German Regulation" by Dominika Paula Gałkiewicz, March 2015.

018 "Manager Characteristics and Credit Derivative Use by U.S. Corporate Bond Funds" by Dominika Paula Gałkiewicz, March 2015.

019 "Measuring Connectedness of Euro Area Sovereign Risk" by Rebekka Gätjen Melanie Schienle, April 2015.

020 "Is There an Asymmetric Impact of Housing on Output?" by Tsung-Hsien Michael Lee and Wenjuan Chen, April 2015.

021 "Characterizing the Financial Cycle: Evidence from a Frequency Domain Analysis" by Till Strohsal, Christian R. Proaño and Jürgen Wolters, April 2015.

\section{SFB 649, Spandauer Straße 1, D-10178 Berlin http://sfb649.wiwi.hu-berlin.de}




\section{SFB 649 Discussion Paper Series 2015}

For a complete list of Discussion Papers published by the SFB 649, please visit http://sfb649.wiwi.hu-berlin.de.

022 "Risk Related Brain Regions Detected with 3D Image FPCA" by Ying Chen, Wolfgang K. Härdle, He Qiang and Piotr Majer, April 2015.

023 "An Adaptive Approach to Forecasting Three Key Macroeconomic Variables for Transitional China" by Linlin Niu, Xiu Xu and Ying Chen, April 2015.

024 "How Do Financial Cycles Interact? Evidence from the US and the UK" by Till Strohsal, Christian R. Proaño, Jürgen Wolters, April 2015.

025 "Employment Polarization and Immigrant Employment Opportunities" by Hanna Wielandt, April 2015.

026 "Forecasting volatility of wind power production" by Zhiwei Shen and Matthias Ritter, May 2015.

027 "The Information Content of Monetary Statistics for the Great Recession: Evidence from Germany" by Wenjuan Chen and Dieter Nautz, May 2015.

028 "The Time-Varying Degree of Inflation Expectations Anchoring" by Till Strohsal, Rafi Melnick and Dieter Nautz, May 2015. 